\title{
Effects of xylo-oligosaccharide and flavomycin on the immune function of broiler chickens
}

\author{
Lin Yuan ${ }^{1}$, Li Wan Li ${ }^{1}$, Qian Qian Huo ${ }^{2}$, Hong Chen Du ${ }^{2}$, Xiang Zhi Wang ${ }^{2}$, Di Bao Yi ${ }^{1}$, Fa Ming Wang \\ Corresp. 1 \\ ${ }^{1}$ Henan Academy of Agricultural Sciences, Henan Key Laboratory of Farm Animal Breeding and Nutritional Regulation, Institute of animal husbandry and \\ veterinary medicine, Zhengzhou, Henan, China \\ 2 Henan Agricultural University, College of Animal Science and Veterinary Medicine, Zhengzhou, Henan, China \\ Corresponding Author: Fa Ming Wang \\ Email address: wangmingfa2008@126.com
}

This study investigated the effects of xylo-oligosaccharide (XOS) and flavomycin (FLA) on the performance and immune function of broiler chickens. A total of 150 ArborAcres broilers were randomly divided into three groups and fed for 6 weeks from 1 day of age in cascade cages. The diets of each test group were 1) a basal diet, 2) the basal diet supplemented with $2 \mathrm{mg} / \mathrm{kg}$ FLA, and 3) the basal diet supplemented with $2 \mathrm{mg} / \mathrm{kg} \mathrm{XOS}$. At 21 and 42 days, the growth performance index values and short-chain fatty acid (SCFA) concentrations in the cecum were quantified. Furthermore, immunoglobulin $\mathrm{G}$ (IgG) and plasma interleukin 2 (IL-2) as well as mRNA expression of LPS-Induced TNF-alpha Factor (LITAF), Toll-like receptor-5 (TLR5) and interferon gamma (IFNY) in the jejunum were quantified. The results showed that administration of XOS or FLA to chickens significantly improved the average daily gain. Supplementation with XOS increased acetate and butyrate in the cecum, while FLA supplementation increased propionate in the cecum. An increase in plasma IgG was observed in XOS-fed 21-day-old broilers, but FLA supplementation decreased IgG in the plasma of 42-day-old broilers and increased plasma IL-2. Furthermore, FLA or XOS supplementation downregulated mRNA expression of IFN $\gamma$, LITAF and TLR5. The above data suggest that addition of XOS and FLA to the diet could improve the growth performance of broilers, reduce the expression of cytokine genes by stimulating SCFA. 
1 Effects of xylo-oligosaccharide and flavomycin on the 2 immune function of broiler chickens

3 Yuan $L^{1}$, Li W L ${ }^{1}$, Huo $Q Q^{2}$, Du C H', Wang Z X X $^{2}$, Yi B D ${ }^{1}$, Wang M F

$4{ }^{1}$ Henan Key Laboratory of Farm Animal Breeding and Nutritional Regulation, Institute of animal

5 husbandry and veterinary medicine, Henan Academy of Agricultural Sciences, Zhengzhou,

6 China.

$7{ }^{2}$ College of Animal Science and Veterinary Medicine, Henan Agricultural University, Zhengzhou,

8 China

9 Corresponding author: Wang M F

10 Email address: wangmingfa2008@126.com

\section{ABSTRACT}

This study investigated the effects of xylo-oligosaccharide (XOS) and flavomycin (FLA) on the performance and immune function of broiler chickens. A total of 150 ArborAcres broilers were randomly divided into three groups and fed for 6 weeks from 1 day of age in cascade cages. The diets of each test group were 1) a basal diet, 2) the basal diet supplemented with $2 \mathrm{mg} / \mathrm{kg}$ FLA, and 3) the basal diet supplemented with $2 \mathrm{mg} / \mathrm{kg}$ XOS. At 21 and 42 days, the growth performance index values and short-chain fatty acid (SCFA) concentrations in the cecum were quantified. Furthermore, immunoglobulin $\mathrm{G}$ (IgG) and plasma interleukin 2 (IL-2) as well as mRNA expression of LPS-Induced TNF-alpha Factor (LITAF), Toll-like receptor-5 (TLR5) and interferon gamma $(I F N \gamma)$ in the jejunum were quantified. The results showed that administration of XOS or FLA to chickens significantly improved the average daily gain. Supplementation with XOS increased acetate and butyrate in the cecum, while FLA supplementation increased propionate in the cecum. An increase in plasma IgG was observed in XOS-fed 21-day-old broilers, but FLA supplementation decreased IgG in the plasma of 42-day-old broilers and increased plasma IL-2. Furthermore, FLA or XOS supplementation downregulated mRNA expression of IFN $\gamma, L I T A F$ and TLR5. The above data suggest that addition of XOS and FLA to the diet could improve the growth performance of broilers, reduce the expression of cytokine genes by stimulating SCFA.

\section{INTRODUCTION}

Antibiotic growth promoters (AGPs) could improve growth performance and disease resistance and have been widely used in poultry diets (Castanon 2007). However, due to growing concern about the spread of antibiotic-resistant genes in human and animal pathogens, the European Union has limited or even prohibited the use of antibiotics in the poultry breeding industry since 2006 (Maron et al. 2013). However, poultry feed without AGPs may increase the incidence of 
disease and lead to an increase in the use of antibiotics for treatment (Casewell et al. 2003). Therefore, it is necessary to find an effective alternative to AGPs to ensure the health of poultry as well as the safe and efficient production of poultry products.

FLA is absorbed poorly after oral administration and thus highly valued as a feed additive growth promoter in livestock animals with negligible safety concerns with very low residual concentrations in the tissue of food animals (Pfaller 2006). Studies have shown that AGPs mainly act on intestinal microbes to improve their metabolic activity and immune function (Dibner \& Richards 2005; Oakley et al. 2014), and the complex microbial community in the intestine interacts with the host animal and affects its health. Therefore, it is possible to adjust the intestinal flora through the use of probiotics to affect the intestinal and overall health of an animal (Fukuda \& Ohno 2014). Studies have shown that the probiotic agents that have regulatory effects on microbes are primarily Bifidobacterium spp. and Lactobacillus spp. (Gibson 2004; Holck et al. 2011; Thomassen et al. 2011; Vigsnaes et al. 2011), and they have been proven to have beneficial effects in animals (Rastall 2007). The final product of the fermentation of dietary fiber by bacteria is mainly short chain fatty acids (SCFA), but this process also provides the host with a variety of prebiotics that regulate intestinal inflammation (Arpaia et al. 2013; Smith et al. 2013).

Previous studies have shown that xylo-oligosaccharide (XOS)-selective fermentation can improve host health by inducing structural changes in the intestinal flora, indicating that XOS meets the definition of a prebiotic (Gibson et al. 2004). The study on mice show that XOS feeding decreases systemic inflammation, and this effect is most likely caused by higher SCFA concentrations as a result of an increased bifidobacterial saccharolytic fermentation in the entire gut and not only in the large intestine, in the intestinal epithelium, expression of interleukin $1 \beta$ $(I l 1 \beta)(P<0.01)$ and interferon gamma $(I F N \gamma)(P<0.05)$ was significantly less in blood from XOSfed mice than from control-fed mice. In vitro treatment of blood with propionate significantly decreased Ill $\beta(P<0.01), I F N \gamma(P<0.05)$, and interleukin 18 (Ill $)(P<0.001)$ expression, increased production of SCFA in the gut, which are transported across the intestine and into the systemic compartments, results in downregulation of low-grade inflammatory cytokines (Hansen et al. 2013).

In conclusion, it is important to study the effect of XOS on the relative expression level of immune genes in the intestines of broiler chickens. Therefore, the current study assessed the effects of antibiotic flavomycin (FLA) and XOS on cecal SCFA concentrations, the plasma levels of immunoglobulin $\mathrm{G}(\mathrm{IgG})$ and interleukin 2 (IL-2) and the expression of $I F N \gamma$, LPS-Induced TNF-alpha Factor (LITAF) and Toll-like receptor-5 (TLR5) in the jejunum of broilers to explain possible beneficial effects on gastrointestinal health.

\section{MATERIALS AND METHODS}

\section{Chickens and diets}

One hundred fifty one-day-old broilers (Ross-308) were divided into three treatment groups (5 replicates, 10 chickens each) as follows: 1) CTL: a basal corn-soybean meal diet as a control, 2) FLA: diet 1 supplemented with flavomycin ( $2 \mathrm{mg}$ active ingredient/ $\mathrm{kg}$ feed), and 3) XOS: diet 1 supplemented with XOS (2 mg/kg feed). The compounds were uniformly mixed in the basal diet. 
75 Broilers were reared in battery cages with raised wire flooring, received feed and water ad libitum for 42 days, and were provided artificial light for $24 \mathrm{~h}$. The temperature remained at 33$35^{\circ} \mathrm{C}$ in the first week and was then gradually decreased to $24^{\circ} \mathrm{C}$ after three weeks. The diets were fed in mash form and formulated according to NRC requirements (Table 1), and the animal use protocol followed the Guide for the Care and Use of Laboratory Animals as adopted and promulgated by the United National Institutes of Health and approved by the Institutional Animal Care and Use Committee of the Henan Academy of Agricultural Sciences (Protocol no. 20170327).

Sample collection

After fasting for $12 \mathrm{~h}$, broilers were weighed at 21 and 42 days, and the average daily feed intake (ADFI), average daily gain (ADG) and feed to gain ratio (FGR) were recorded and calculated on a cage-by-cage basis on days 21 and 42 .

At 21 and $42 \mathrm{~d}$ of age, one chick was selected from each replicate, $3 \mathrm{ml}$ of blood were taken from the wing vein, placed in the anticoagulant tube, and centrifuged at $1000 \times \mathrm{g}$ for $15 \mathrm{~min}$ to separate the plasma and then stored at $-20^{\circ} \mathrm{C}$ until further analysis. The chickens were anesthetized and then killed by jugular bleeding. The cecal chyme and mid-jejunum $(5 \mathrm{~cm}$ from Meckel's diverticulum) were immediately frozen in liquid nitrogen and then stored at $-70^{\circ} \mathrm{C}$.

\section{Cecal SCFA concentrations}

Two $g$ of cecal chyme were placed in a centrifuge tube followed by the addition of $5 \mathrm{ml}$ of ultrapure water, vortex shock for $5 \mathrm{~min}$, and $5,000 \times \mathrm{g}$ centrifugation for $10 \mathrm{~min}$. Next, $1 \mathrm{ml}$ of the supernatant was placed in a plastic ampere tube; $0.2 \mathrm{ml}$ of $25 \%$ phosphoric acid solution was added; and the resulting solution was placed in an ice bath for $30 \mathrm{~min}$ followed by $10,000 \times \mathrm{g}$ centrifugation for $10 \mathrm{~min}$. Then, the supernatant was analyzed on a Hewlett Packard Agilent 6890 gas chromatograph (Agilent, Palo Alto, CA, USA) to determine the concentrations of cecal chyme acetic acid, propionic acid and butyric acid.

\section{Measurement of plasma immunological parameters}

The plasma concentrations of IgG (No. E026) were spectrophotometrically measured using commercial diagnostic kits, and the IL-2 (No. H003) concentrations were quantified using commercially available ELISA test kits (Nanjing Jiancheng Biotechnology Institute, Nanjing, P.R. China).

\section{Determination of the mRNA expression of immune genes}

The relative expression levels of IFN $\gamma, L I T A F$ and TLR5 were detected by RT-PCR. We extracted total RNA from approximately $50 \mathrm{mg}$ of the mid-jejunum using TRIzol reagent (Takara, Dalian, China), and the purity of the isolated RNA was evaluated as previously described(Wang et al., 2012). Total RNA samples were prepared according to the instructions for the commercial kit (TaKaRa, Japan) used to prepare the reverse transcription reaction solution. The total system was $10 \mu \mathrm{L}$, and the reverse transcription product (cDNA) was stored at $-20^{\circ} \mathrm{C}$. The primers were synthesized by the Sangon Biological Engineering Technology \& Service Co., Ltd. (Shanghai, P.R. China), and the jejunum IFN, LITAF and TLR5 primer pairs were designed based on the 
114 115

IFN $\gamma$, LITAF and TLR5 coding sequences, respectively. The glyceraldehyde-3-phosphate dehydrogenase (GAPDH) primer pair was designed based on the conserved GAPDH sequence (Table 2), and real-time quantitative PCR was performed on a Bio-Rad CFX96 ${ }^{\mathrm{TM}}$ Real-Time PCR System using the EvaGreen dye method. The $20-\mu \mathrm{L}$ reaction system was as follows: SsoFast ${ }^{\mathrm{TM}}$ EvaGreen $^{\circledR}$ Supermix $\times 10 \mu \mathrm{L}$ (Bio-Rad, USA), $1.0 \mu \mathrm{L}$ of the upstream and downstream primers $(100 \mu \mathrm{mol} / \mathrm{L}), 2.0 \mu \mathrm{L}$ of the cDNA template, and the addition of sterilized deionized water to 20 $\mu \mathrm{L}$. The samples were packed in 96-well plates (Bio-Rad, USA), and the reaction conditions were as follows: $95^{\circ} \mathrm{C}$ for $10 \mathrm{~s}$ to pre-denaturation, $95^{\circ} \mathrm{C}$ for $5 \mathrm{~s}$ to denaturation, and $60^{\circ} \mathrm{C}$ for $34 \mathrm{~s}$ to annealing and extension. The quantity of immune gene mRNA in each sample was normalized to GAPDH. The cDNA of the immune genes was quantified using relative standard-curve methods, and the mRNA levels were quantified by the comparison threshold method(Livak and Schmittgen, 2001).

\section{Statistical analysis}

The data were analyzed using SAS 8.0 statistical software. The results were expressed as the mean \pm standard deviation, and pairwise differences were determined by Duncan's test. Differences were considered statistically significant at $P<0.05$.

\section{RESULTS}

\section{Performance}

The growth performance results are presented in Table 3. At 1-21 days, supplementary FLA or XOS had no effect on the average daily feed intake (ADFI), the average daily gain (ADG) or the feed conversion ratio (FCR) $(P>0.05)$. Compared to the control at 1-42 days, ADFI was significantly enhanced with XOS supplementation $(P=0.001)$; ADG was significantly enhanced with FLA $(P=0.047)$ or XOS $(P=0.001)$ supplementation; but supplementing FLA $(P=0.08)$ or XOS $(P=0.074)$ had no effect on FCR compared to the control (Raw_data-table. 3$)$.

\section{SCFA in the cecum}

The cecal SCFA results are presented in Fig 1. At days 21 and 42, the cecal acetate concentration was significantly higher in the control group than in the FLA group $(P<0.001)$, but was significantly lower than in the XOS group ( $21 \mathrm{~d}: P=0.003,42 \mathrm{da}: P<0.001)$. The cecal propionate concentration was significantly higher in the FLA group than the control group ( $21 \mathrm{~d}: P=0.001$, $42 \mathrm{~d}: P<0.001)$ and the XOS group(21 d: $P=0.025,42 \mathrm{~d}: P=0.005)$ on days 21 and 42 . Cecal butyrate was higher for the XOS group than for the CTL $(P<0.001)$ or FLA $(P<0.001)$ groups at both 21 and $42 \mathrm{~d}$ (Raw_data-figure. 1).

\section{Immune-related factors in the plasma}

The results for immune-related factors in the plasma of broiler chickens are presented in Table 4. At 21 days of age, the IgG in the XOS group was significantly higher than in the control $(P=0.002)$ and FLA $(P<0.039)$ groups, and at 42-day-age, the IgG in the FLA group was significantly lower than in the control $(P=0.035)$ and XOS $(P=0.008)$ groups. The IL-2 in the FLA group was significantly lower $(P<0.05)$ than in the control $(21 \mathrm{~d}: P=0.03,42 \mathrm{~d}: P=0.002)$ 
152

153

154

155

156

157

158

159

160

161

162

163

164

165

166

167

168

169

170

171

172

173

174

175

176

177

178

179

180

181

182

183

184

185

186

187

188

189

190

191

and XOS (21 d: $P=0.024,42 \mathrm{~d}: P<0.001)$ groups on days 21 and 42 (Raw_data-table. 4).

\section{Relative mRNA expression of immune genes}

The results for relative mRNA expression of immune genes are presented in Fig 2. Compared to the control group, the FLA and XOS treatments had decreased mRNA levels of jejunum $I F N \gamma$, LITAF and TLR5 $(P<0.001)$ on days 21 and 42. At 21 day of age, the jejunum $\operatorname{IFN\gamma }(P=0.002)$ and TLR5 $(P=0.001)$ mRNA levels were significantly higher in the FLA group than in the XOS group, and at 42 days of age, the jejunum LITAF mRNA level was significantly higher $(P=0.013)$ in the XOS group than in the FLA group (Raw_data-figure. 2).

\section{DISCUSSION}

As a prebiotic, XOS can be used to selectively alter the structure and activity of the gastrointestinal flora by selective fermentation, thereby improving host health (Gibson et al. 2004), and FLA can prevent animal diseases and promote growth and thus is widely used in poultry feed. In this study, broilers with XOS- and FLA-supplemented diets had greater ADG than those of the control group, which agrees with the studies by De et al. (De et al. 2015) and Zhenping et al. (Zhenping et al. 2013). We speculate that may be attributed to the regulation of XOS on intestinal microbes, there is significant difference in the Firmicutes phylum (1.3-fold higher) in the cecum content of the XOS-fed mice than measured in the control-fed mice (Hansen et al. 2013), when the proportion of Firmicutes phylum in the intestine increases, the ability of the host to absorb the energy in the food will be strengthened, and the storage of fat in the body will be increased (Ley et al. 2005). These results show that adding XOS to the diet can improve the biological function of chickens, suggesting that XOS could be considered an emerging prebiotic, which is defined as a food ingredient that has no nutritional value but can improve the health of the host by regulating its microflora.

Previous studies have shown that XOS is not readily digestible by the gastrointestinal tract or that it has low digestibility overall, ensuring that it can reach the colon (Imaizumi et al. 1991; Nakakuki 1993). Although XOS is not degraded by gastrointestinal digestive enzymes, it can be fermented by intestinal microbes to produce SCFA (Kabel et al. 2002). Our results demonstrate that XOS could increase the levels of acetate and butyrate in the cecum of broilers, SCFA may be the key factor in the mechanisms behind the immune-modulatory effect of XOS seen systemically (Hansen et al. 2013). The level of plasma IgG in the XOS group of broilers significantly increased compared with the other two groups at 21 days, suggesting that XOS could improve broiler immune function. Furthermore, the plasma IL-2 concentration of the FLA test group was lower than that of the control group; IL-2 is a proinflammatory cytokine, which can promote the growth, proliferation and differentiation of $\mathrm{T}$ cells (Yang et al. 2015). Interleukins belong to a class of cytokines that function in the immune system by playing an important physiological and pathological role in the inflammatory response process. A cytokine secretion imbalance or cytokine process disorders may lead to a variety of pathological disorders (Tayal \& Kalra 2008), indicating that the broilers in the FLA group had less of an inflammatory reaction during growth. Previous research has also found that the addition of virginiamycin in broilers significantly increases the concentration of propionate in the cecum (Pourabedin et al. 
192

193

194

195

196

197

198

199

200

201

202

203

204

205

206

207

208

209

210

211

212

213

214

215

216

217

218

219

220

221

222

223

224

225

226

227

228

229

2015). In poultry, SCFA enhances intestinal, non-specific immune mechanisms by stimulating the expression of mucin glycoprotein in intestinal epithelial cells to combat pathogens, thus affecting growth performance (L E M Willemsen 2003; Timbermont et al. 2010). Butyrate is the main source of energy for colon cells and can have anti-inflammatory effects through a number of mechanisms (Hamer et al. 2008). Butyrate can inhibit the expression of nuclear factor kappa B $(\mathrm{NF}-\kappa \mathrm{B})$, which is an important transcription factor that regulates the expression of proinflammatory cytokines (Inan et al. 2000). Butyrate can also interfere with the signal transduction of interferon gamma $(I F N \gamma)$ by inhibiting the activation of signal transducers and the activator of transcription 1 (STAT1) (Klampfer et al. 2003). Studies have also shown that butyrate can enhance the expression of peroxisome proliferator-activated receptor gamma (PPAR- $\gamma$ ), a transcription factor that belongs to the nuclear hormone receptor family that can reduce the expression of inflammatory cytokines and promote immune cell differentiation and this has an anti-inflammatory function (Martin 2009; Schwab et al. 2007; Wächtershäuser et al. 2000).

The intestinal immune system has a complicated relationship with intestinal microorganisms (Chow et al. 2010; Liu et al. 2017); intestinal commensal flora could effectively inhibit the intestinal inflammatory response and promote immune tolerance through the Toll-like receptor pathway (Round et al. 2011). Pourabedin et al (Pourabedin et al. 2015) and Maesschalck et al (Maesschalck et al. 2015) determined the effect of XOS and virginiamycin on the microbes in the intestine of broiler chickens by $16 \mathrm{~S}$ rRNA pyrophosphate sequencing, and the results showed that the addition of XOS and virginiamycin to diets could regulate the relative abundance of intestinal flora. In this study, broilers fed FLA and XOS significantly downregulated the mRNA levels of jejunal LITAF, IFN $\gamma$ and TLR5 compared to the controls. LITAF is a proinflammatory cytokine that is mainly produced by macrophages and monocytes and is involved in normal inflammatory and immune responses. LITAF has been shown to increase under many pathological conditions such as in the presence of bacterial toxins, IL-1, IL-2, IFN and other cytokines as well as sepsis, malignancies, heart failure and many others (Ghareeb et al. 2013). TLR5 can bind to bacterial flagellin and activate proinflammatory cytokines for a proinflammatory response. A previous study showed that host recognition of flagellin can accelerate the aggregation of neutrophils, thereby protecting the host from pathogens (Ferro et al. 2004; Vijaykumar et al. 2007). The results of this study indicate that the addition of XOS and FLA in the diet can improve the immune function of broilers by reducing the expression of cytokine genes in the jejunum of broilers.

\section{CONCLUSION}

Overall, the present findings showed that the addition of XOS and FLA to the diet can improve the growth performance of broilers. The resulting production of SCFA by supplementing XOS and FLA may thus be the indirect cause of the reduced expression of LITAF, IFN $\gamma$ and TLR5.

\section{REFERENCES}

Arpaia N, Campbell C, Fan X, Dikiy S, van der Veeken J, deRoos P, Liu H, Cross JR, Pfeffer K, Coffer PJ, and

Peer) reviewing PDF | (2017:12:22762:1:1:NEW 2 Feb 2018) 
Rudensky AY. 2013. Metabolites produced by commensal bacteria promote peripheral regulatory T-cell generation. Nature 504:451-455. 10.1038/nature12726

Casewell M, Friis C, Marco E, McMullin P, and Phillips I. 2003. The European ban on growth-promoting antibiotics and emerging consequences for human and animal health. $J$ Antimicrob Chemother 52:159-161. $10.1093 / \mathrm{jac} / \mathrm{dkg} 313$

Castanon JI. 2007. History of the use of antibiotic as growth promoters in European poultry feeds. Poult Sci 86:2466-2471. 10.3382/ps.2007-00249

Chow J, Lee SM, Shen Y, Khosravi A, and Mazmanian SK. 2010. Host-bacterial symbiosis in health and disease. Advances in Immunology 107:243-274.

De MC, Eeckhaut V, Maertens L, De LL, Marchal L, Nezer C, De BS, Croubels S, Daube G, and Dewulf J. 2015. Effects of Xylo-Oligosaccharides on Broiler Chicken Performance and Microbiota. Applied \& Environmental Microbiology 81:5880.

Dibner JJ, and Richards JD. 2005. Antibiotic growth promoters in agriculture: history and mode of action. Poult Sci 84:634-643.

Ferro PJ, Swaggerty CL, Kaiser P, Pevzner IY, and Kogut MH. 2004. Heterophils isolated from chickens resistant to extra-intestinal Salmonella enteritidis infection express higher levels of pro-inflammatory cytokine mRNA following infection than heterophils from susceptible chickens. Epidemiology \& Infection 132:1029-1037.

Fukuda S, and Ohno H. 2014. Gut microbiome and metabolic diseases. Seminars in Immunopathology: Springer. $p$ 103-114.

Ghareeb K, Awad WA, Soodoi C, Sasgary S, Strasser A, and Bohm J. 2013. Effects of feed contaminant deoxynivalenol on plasma cytokines and mRNA expression of immune genes in the intestine of broiler chickens. PLoS One 8:e71492. 10.1371/journal.pone.0071492

Gibson G. 2004. From probiotics to prebiotics and a healthy digestive system. Journal of food Science 69:M141M143.

Gibson GR, Probert HM, Loo JV, Rastall RA, and Roberfroid MB. 2004. Dietary modulation of the human colonic microbiota: updating the concept of prebiotics. Nutr Res Rev 17:259-275. 10.1079/nrr200479

Hamer HM, Jonkers D, Venema K, Vanhoutvin S, Troost FJ, and Brummer RJ. 2008. Review article: the role of butyrate on colonic function. Alimentary Pharmacology \& Therapeutics 27:104-119.

Hansen CH, Frã, Kiã)'R H, Christensen AG, Bergstrã $\mid M$ A, Licht TR, Hansen AK, and Metzdorff SB. 2013. Dietary xylooligosaccharide downregulates IFN- $\hat{I}^{3}$ and the low-grade inflammatory cytokine IL- $1 \hat{\mathrm{I}}^{2}$ systemically in mice. Journal of Nutrition 143:533-540.

Holck J, Lorentzen A, Vigsnaes LK, Licht TR, Mikkelsen JD, and Meyer AS. 2011. Feruloylated and nonferuloylated arabino-oligosaccharides from sugar beet pectin selectively stimulate the growth of Bifidobacterium spp. in human fecal in vitro fermentations. $J$ Agric Food Chem 59:6511-6519. 10.1021/jf200996h

Imaizumi K, Nakatsu Y, Sato M, Sedarnawati Y, and Sugano M. 1991. Effects of Xylooligosaccharides on Blood Glucose, Serum and Liver Lipids and Cecum Short-chain Fatty Acids in Diabetic Rats. Agricultural \& Biological Chemistry 55:199-205.

Inan MS, Rasoulpour RJ, Yin L, Hubbard AK, Rosenberg DW, and Giardina C. 2000. The luminal short-chain fatty acid butyrate modulates NF-kappaB activity in a human colonic epithelial cell line. Gastroenterology 118:724-734.

Kabel MA, Kortenoeven L, And HAS, and Voragen AGJ. 2002. In Vitro Fermentability of Differently Substituted Xylo-oligosaccharides. Journal of Agricultural \& Food Chemistry 50:6205-6210.

Klampfer L, Huang J, Sasazuki T, Shirasawa S, and Augenlicht L. 2003. Inhibition of interferon gamma signaling by 
the short chain fatty acid butyrate. Molecular Cancer Research Mcr 1:855.

L E M Willemsen MAK, S J H van Deventer, E A F van Tol. 2003. Short chain fatty acids stimulate epithelial mucin 2 expression through differential effects on prostaglandin $\mathrm{E}(1)$ and $\mathrm{E}(2)$ production by intestinal myofibroblasts. 52:1442-1447.

Ley RE, Bäckhed F, Turnbaugh P, Lozupone CA, Knight RD, and Gordon JI. 2005. Obesity Alters Gut Microbial Ecology. Proceedings of the National Academy of Sciences of the United States of America 102:1107011075.

Liu G, Ren W, Fang J, Hu CA, Guan G, Al-Dhabi NA, Yin J, Duraipandiyan V, Chen S, Peng Y, and Yin Y. 2017. LGlutamine and L-arginine protect against enterotoxigenic Escherichia coli infection via intestinal innate immunity in mice. Amino Acids. 10.1007/s00726-017-2410-9

Maesschalck CD, Eeckhaut V, Maertens L, Lange LD, Marchal L, Nezer C, Baere SD, Croubels S, Daube G, and Dewulf J. 2015. Effects of Xylo-Oligosaccharides on Broiler Chicken Performance and Microbiota. Applied \& Environmental Microbiology 81:5880.

Maron DF, Smith TJ, and Nachman KE. 2013. Restrictions on antimicrobial use in food animal production: an international regulatory and economic survey. Global Health 9:48. 10.1186/1744-8603-9-48

Martin H. 2009. Role of PPAR-gamma in inflammation. Prospects for therapeutic intervention by food components. Mutation Research 669:1.

Nakakuki T. 1993. Oligosaccharides : production, properties and applications: Gordon and Breach Science Publishers.

Oakley BB, Lillehoj HS, Kogut MH, Kim WK, Maurer JJ, Pedroso A, Lee MD, Collett SR, Johnson TJ, and Cox NA. 2014. The chicken gastrointestinal microbiome. FEMS Microbiology Letters 360:100-112.

Pfaller MA. 2006. Flavophospholipol use in animals: positive implications for antimicrobial resistance based on its microbiologic properties. Diagnostic Microbiology \& Infectious Disease 56:115.

Pourabedin M, Guan L, and Zhao X. 2015. Xylo-oligosaccharides and virginiamycin differentially modulate gut microbial composition in chickens. Microbiome 3:1-12.

Rastall B. 2007. Prebiotics. In Chemical and functional properties of food components. Boca Raton, FL, USA: CRC Press.

Round JL, Lee SM, Li J, Tran G, Jabri B, Chatila TA, and Mazmanian SK. 2011. The Toll-like receptor pathway establishes commensal gut colonization. Science 332:974-977.

Schwab M, Reynders V, Loitsch S, Steinhilber D, Stein J, and Schröder O. 2007. Involvement of different nuclear hormone receptors in butyrate-mediated inhibition of inducible $\mathrm{NF \kappa B}$ signalling. Molecular Immunology 44:3625-3632.

Smith PM, Howitt MR, Panikov N, Michaud M, Gallini CA, Bohlooly YM, Glickman JN, and Garrett WS. 2013. The microbial metabolites, short-chain fatty acids, regulate colonic Treg cell homeostasis. Science 341:569573. $10.1126 /$ science. 1241165

Tayal V, and Kalra BS. 2008. Cytokines and anti-cytokines as therapeutics - An update. European Journal of Pharmacology 579:1.

Thomassen LV, Vigsnaes LK, Licht TR, Mikkelsen JD, and Meyer AS. 2011. Maximal release of highly bifidogenic soluble dietary fibers from industrial potato pulp by minimal enzymatic treatment. Appl Microbiol Biotechnol 90:873-884. 10.1007/s00253-011-3092-y

Timbermont L, Lanckriet A, Dewulf J, Nollet N, Schwarzer K, Haesebrouck F, Ducatelle R, and Immerseel FV. 2010. Control of Clostridium perfringens-induced necrotic enteritis in broilers by target-released butyric acid, fatty acids and essential oils. Avian Pathology 39:117. 
316 Vigsnaes LK, Holck J, Meyer AS, and Licht TR. 2011. In Vitro Fermentation of Sugar Beet ArabinoOligosaccharides by Fecal Microbiota Obtained from Patients with Ulcerative Colitis To Selectively Stimulate the Growth of Bifidobacterium spp. and Lactobacillus spp. Appl Environ Microbiol 77:83368344. 10.1128/aem.05895-11

Vijaykumar M, Sanders CJ, Taylor RT, Kumar A, Aitken JD, Sitaraman SV, Neish AS, Uematsu S, Akira S, and Williams IR. 2007. Deletion of TLR5 results in spontaneous colitis in mice. Journal of Clinical Investigation 117:3909.

Wächtershäuser A, Loitsch SM, and Stein J. 2000. PPAR-gamma is selectively upregulated in Caco-2 cells by butyrate. Biochemical \& Biophysical Research Communications 272:380-385.

Yang J, Liu L, Sheikhahmadi A, Wang Y, Li C, Jiao H, Lin H, and Song Z. 2015. Effects of Corticosterone and Dietary Energy on Immune Function of Broiler Chickens. PLoS One 10:e0119750.

Zhenping S, Wenting L, Ruikui Y, Jia L, Honghong L, Wei S, Zhongmie W, Jingpan L, Zhe S, and Yuling Q. 2013. Effect of a straw-derived xylooligosaccharide on broiler growth performance, endocrine metabolism, and immune response. Canadian journal of veterinary research = Revue canadienne de recherche vétérinaire $77: 105$. 


\section{Table $\mathbf{1}$ (on next page)}

Diet compositions and nutrient levels

${ }^{1}$ Premix provided per kg of diet: vitamin A, 15000 IU; vitamin D3, 3000 IU; vitamin E, 20 IU; VK, $3 \mathrm{mg}$; thiamine, $4 \mathrm{mg}$; riboflavin, $8 \mathrm{mg}$; vitamin B5, $40 \mathrm{mg}$; pyridoxine, $4.5 \mathrm{mg}$; vitamin B12, $0.02 \mathrm{mg}$; pantothenic acid, $30 \mathrm{mg}$; niacin, $35 \mathrm{mg}$; choline, $1300 \mathrm{mg}$; folic acid, $1.2 \mathrm{mg}$; biotin, $0.18 \mathrm{mg}$; Cu (copper sulfate), $8 \mathrm{mg}$; Fe (ferrous sulfate), $80 \mathrm{mg}$; Zn (zinc sulfate), 75 mg; Mn (manganese sulfate), $100 \mathrm{mg}$; I (potassium iodide), $0.4 \mathrm{mg}$; Se (sodium selenite), $0.15 \mathrm{mg}$. 
Manuscript to be reviewed

\begin{tabular}{|l|c|c|}
\hline Parameter & $1-21 \mathrm{~d}$ & $22-42 \mathrm{~d}$ \\
\hline Ingredients, \% & & \\
\hline Corn & 55.63 & 60.17 \\
\hline Soybean meal & 38.00 & 33.00 \\
\hline Limestone & 1.10 & 1.10 \\
\hline Dicalcium phosphate & 1.80 & 1.60 \\
\hline Table salt & 0.30 & 0.30 \\
\hline DL-Methionine & 0.17 & 0.13 \\
\hline Vegetable oil & 2.00 & 2.70 \\
\hline Premix ${ }^{2}$ & 1.00 & 1.00 \\
\hline Nutrient levels & & \\
\hline Metabolic energy, kcal/kg & 2866.80 & 2945.64 \\
\hline Crude protein & 22.07 & 20.13 \\
\hline Met, \% & 0.33 & 0.31 \\
\hline Lys, \% & 1.19 & 1.06 \\
\hline Cys, \% & 0.36 & 0.33 \\
\hline Calcium, \% & 0.91 & 0.85 \\
\hline Non-phytate phosphorus, \% & 0.44 & 0.40 \\
\hline
\end{tabular}




\section{Table 2 (on next page)}

Primer pairs for IFNY, LITAF , TLR5 and GAPDH genes from broilers

The glyceraldehyde-3-phosphate dehydrogenase (GAPDH) primer pair was designed based on the conserved GAPDH sequence 


\begin{tabular}{|c|c|c|}
\hline Primer & Sequence & $\begin{array}{l}\text { Fragment } \\
\text { length (bp) }\end{array}$ \\
\hline \multirow[t]{2}{*}{$I F N \gamma$} & P1 5'-TGAGCCAGATTGTTTCGATG-3' & \multirow[t]{2}{*}{246} \\
\hline & P2 5'-TCCTTTTGAAACTCGGAGGA-3' & \\
\hline \multirow[t]{2}{*}{ LITAF } & P3 5'-TGTGTATGTGCAGCAACCCGTAGT-3' & \multirow[t]{2}{*}{229} \\
\hline & P4 5'-GGCATTGCAATTTGGACAGAAGT-3' & \\
\hline \multirow[t]{2}{*}{ TLR5 } & P5 5'-TGTGGGAGAGAGGTTTATGTTTGG-3' & \multirow[t]{2}{*}{169} \\
\hline & P6 5'-CTGAGAGAGAGGTGAGACAATAGG-3' & \\
\hline \multirow[t]{2}{*}{ GAPDH } & P7 5'-CTACACACGGACACTTCAAG-3' & \multirow[t]{2}{*}{244} \\
\hline & P8 5'-ACAAACATGGGGGCATCAG-3' & \\
\hline
\end{tabular}




\section{Table 3(on next page)}

Effect of FLA and XOS on performance of broilers

Each value represents the mean \pm SD of 5 replicates. In the same row, values with no superscript letter or the same superscript letter are not significantly different $(P>0.05)$; those with different superscript letters are significantly different $(P<0.05)$. ADFI, average daily feed intake; ADG, average daily gain; FCR, feed conversion ratio. 


\begin{tabular}{|c|c|c|c|}
\hline Parameter & CTL & FLA & XOS \\
\hline $1-21$ days & & & \\
\hline ADFI $(\mathrm{g} / \mathrm{d})$ & $50.31 \pm 1.23$ & $51.31 \pm 1.66$ & $50.89 \pm 1.35$ \\
\hline ADG $(\mathrm{g} / \mathrm{d})$ & $32.95 \pm 0.79$ & $33.81 \pm 0.95$ & $33.44 \pm 1.07$ \\
\hline FCR & $1.53 \pm 0.01$ & $1.52 \pm 0.01$ & $1.52 \pm 0.02$ \\
\hline $1-42$ days & & & \\
\hline ADFI $(\mathrm{g} / \mathrm{d})$ & $96.46 \pm 1.26^{\mathrm{b}}$ & $98.36 \pm 1.59^{\mathrm{b}}$ & $101.06 \pm 1.95^{\mathrm{a}}$ \\
\hline ADG $(\mathrm{g} / \mathrm{d})$ & $50.29 \pm 1.04^{\mathrm{b}}$ & $51.83 \pm 1.32^{\mathrm{a}}$ & $53.25 \pm 0.88^{\mathrm{a}}$ \\
\hline FCR & $1.92 \pm 0.02$ & $1.90 \pm 0.02$ & $1.90 \pm 0.01$ \\
\hline
\end{tabular}




\section{Table 4 (on next page)}

Immune-related factors in the plasma of broiler chickens

Each value represents the mean \pm SD of 5 replicates. In the same row, values with no superscript letter or the same superscript letter are not significantly different $(P>0.05)$; those with different superscript letters are significantly different $(P<0.05)$. 


\begin{tabular}{|c|c|c|c|}
\hline & & & \\
& CTL & FLA & XOS \\
\hline $\mathrm{IgG}(\mathrm{mg} / \mathrm{ml})$ & & & \\
\hline & & & \\
\hline 21 days & $2.03 \pm 0.16^{\mathrm{b}}$ & $2.19 \pm 0.13^{\mathrm{b}}$ & $2.45 \pm 0.21^{\mathrm{a}}$ \\
\hline 42 days & $1.52 \pm 0.11^{\mathrm{a}}$ & $1.31 \pm 0.11^{\mathrm{b}}$ & $1.59 \pm 0.18^{\mathrm{a}}$ \\
\hline $\mathrm{IL}-2(\mathrm{ng} / \mathrm{L})$ & & & \\
\hline & & & \\
\hline 21 days & $170.65 \pm 9.32^{\mathrm{a}}$ & $147.84 \pm 16.40^{\mathrm{b}}$ & $171.67 \pm 16.97^{\mathrm{a}}$ \\
\hline & $215.38 \pm 21.01^{\mathrm{a}}$ & $158.27 \pm 24.01^{\mathrm{b}}$ & $227.29 \pm 24.07^{\mathrm{a}}$ \\
\hline 42 days & & & \\
\hline
\end{tabular}




\section{Figure 1 (on next page)}

Short-chain fatty acid concentrations in the cecum $(\mu \mathrm{mol} / \mathrm{g})$.

Acetate, propionate and butyrate concentrations ( $\mu \mathrm{mol} / \mathrm{g}$ content) collected on 21 (A), 42 (B) days of age. In the same row, values with no superscript letter or the same superscript letter are not significantly different $(P>0.05)$; those with different superscript letters are significantly different $(P<0.05)$. 


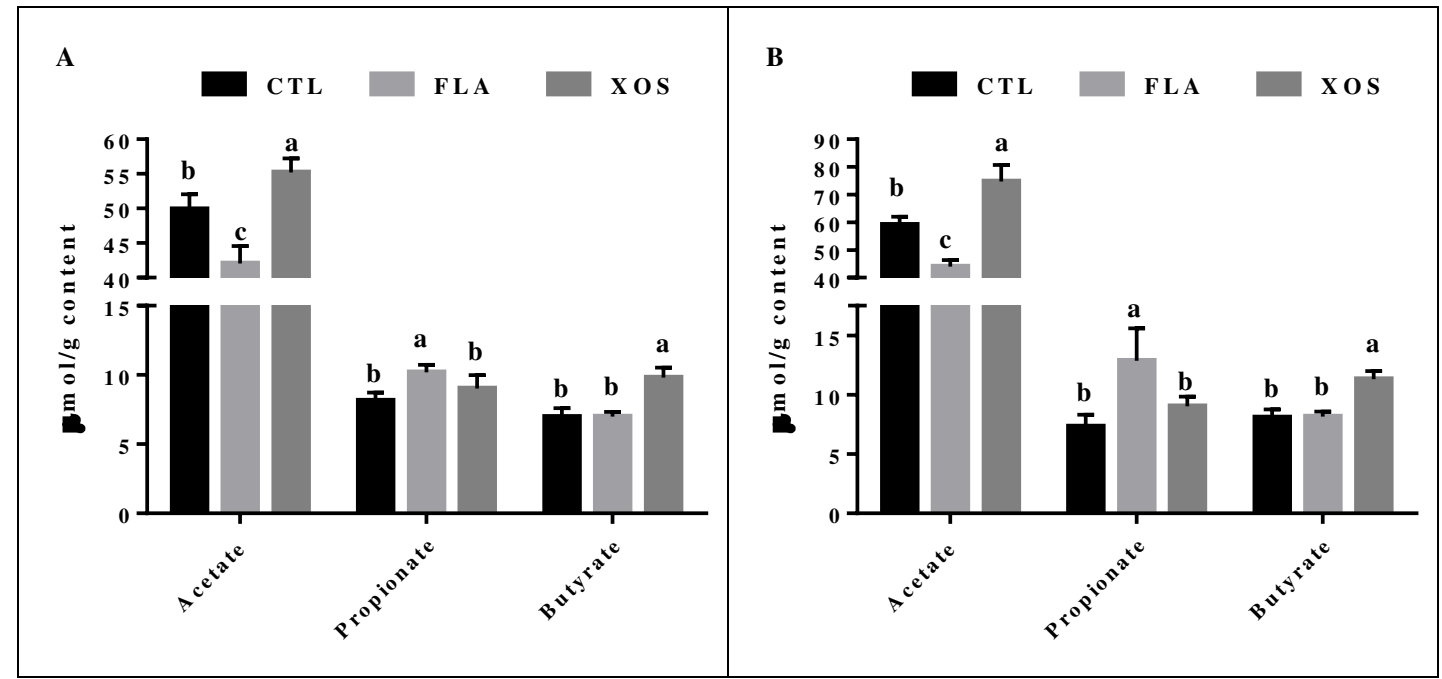




\section{Figure 2 (on next page)}

The relative mRNA expression of immune genes in the jejunal tissues of broiler chickens

IFNY, LITAF and TLR5 mRNA relative expressions collected on 21 (A), 42 (B) days of age. In the same row, values with no superscript letter or the same superscript letter are not significantly different $(P>0.05)$; those with different superscript letters are significantly different $(P<0.05)$. 


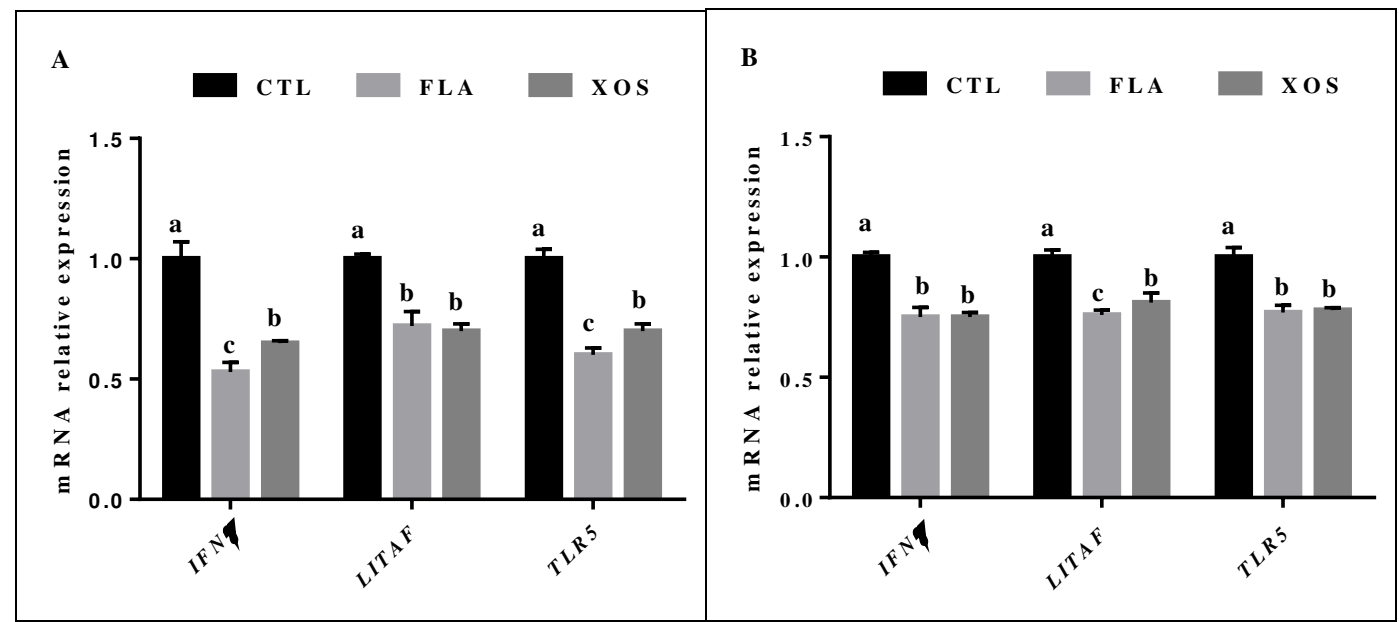

